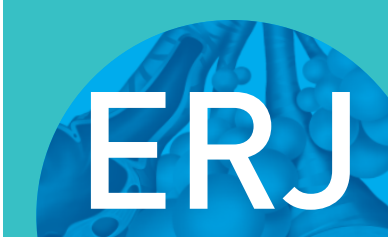

open research

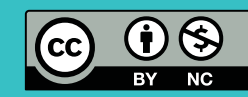

\title{
COVID-19 controversy: when to intubate?
}

\author{
Alyn H Morice
}

Dept of Medicine, Castle Hill Hospital, Cottingham, UK.

Correspondence: Alyn H. Morice, Dept of Medicine, Castle Hill Hospital, Cottingham, HU16 5JQ, UK. E-mail: a.h.moriceahull.ac.uk

@ERSpublications

Opinions differ as to when to escalate ventilatory support to intubation and mechanical ventilation https://bit.ly/3wgmS2B

Cite this article as: Morice AH. COVID-19 controversy: when to intubate? ERJ Open Res 2021; 7: 00185-2021 [https://doi.org/10.1183/23120541.00185-2021].

Today we publish correspondence $[1,2]$ concerning a heated debate on when to institute mechanical ventilation in patients with hypoxaemic respiratory failure due to COVID-19. The decision, of course, rests on the definition of respiratory failure and how to measure it. An almost universal tool is oximetry, which provides us with the percentage of haemoglobin saturated with oxygen in arterial blood. However, this metric is not linearly related to the volume of oxygen released to the tissues for a given cardiac output [3] I have on my phone the oxyhaemoglobin dissociation curve because it illustrates that a fall in top-end saturation impacts oxygen delivery little, much to the surprise of some colleagues.

The correspondence refers to an article by VOSHAAR et al. [4], a retrospective analysis of the outcome of conservative management of patients based on clinical criteria rather than "hypoxia" alone. Unfortunately, as with most journals, we have been deluged with retrospective case series of patients who were given snake oil and recovered. In fact, two thirds of patients admitted to the intensive therapy unit survive [5] so it becomes easy to convince oneself that success is due to treatment. As the great pharmacologist Sir John Gaddum said, "patients may recover in spite of drugs or because of them".

What makes the study by VoshaAR et al. [4] different from this mass of observational reports? They are advocating noninvasive measures unless driven by clinical necessity. That is, do less, rather than more. It is worthy of debate because evidence-based medicine cannot come to our rescue, if it ever does.

The article was expeditiously published (after rapid review) but then we were and are in the grip of a pandemic. ERJ Open Research has recently adopted an Early View format that allows for rapid publication and if we are to contribute, it is surely through dissemination of opinion about vital clinical controversies. Please read the correspondence and make your own mind up.

VOSHAAR et al. [4] make the common error of attributing the phrase primum non nocere to Hippocrates. Of course, Hippocrates never said this since it is Latin and he was Greek. Appropriately enough, in Epidemics (Book I, Chapter XI) he writes "As to diseases, make a habit of two things - to help, or at least to do no harm." First, do no harm is, however, the guiding principle of the Hippocratic School and it is as true today as it was (almost exactly) two and a half thousand years ago. As a medical student I was told the story of a man who was admitted to hospital seriously ill. The physician attends daily and the history taken exhaustively. A few simple tests are done. Gradually, the man recovers and is discharged. The patient receives a bill for 200 guineas. He is outraged and exclaims, "but you did nothing!" The physician replies, "The bill for doing nothing is nothing. The bill for knowing to do nothing is 200 guineas."

The clinical response to the pandemic has been little short of magnificent. My own hospital catchment was, for a couple of weeks, top of the national incidence rate in the UK, a country with amongst the worst mortality rates in Europe. The National Health Service was not overwhelmed and conservative

Copyright $\odot$ The authors 2021. This version is distributed under the terms of the Creative Commons Attribution NonCommercial Licence 4.0. For commercial reproduction rights and permissions contact permissions@ersnet.org 
management the rule. We will never know with absolute certainty whether early or delayed intubation is preferable in managing COVID-19. With this uncertainty, it becomes a matter of philosophy rather than science as to how to manage our patients. The role of this journal is to provide the medium for rational discussion and I commend both sets of authors for engaging in this debate.

Conflict of Interest: A.H. Morice has nothing to disclose

\section{References}

1 Windisch W, Kluge S, Bachmann M, et al. Conservative management of COVID-19 associated hypoxaemia. ERJ Open Res 2021; 7: 00113-2021.

2 Voshaar T, Stais P, Köhler D, et al. Conservative management of COVID-19 associated hypoxaemia. ERJ Open Res 2021; 7: 00134-2021.

3 Hsia CCW. Respiratory function of hemoglobin. N Engl J Med 1998; 338: 239-248.

4 Voshaar T, Stais P, Köhler D, et al. Conservative management of COVID-19 associated hypoxaemia. ERJ Open Res 2021; 7: 00026-2021.

5 Armstrong RA, Kane AD, Kursumovic E, et al. Mortality in patients admitted to intensive care with COVID-19: an updated systematic review and meta-analysis of observational studies. Anaesthesia 2021; 76: 537-548. 